\title{
COGNIÇÃO E AFETIVIDADE NAS TRAJETÓRIAS EMPREENDEDORAS DAS MULHERES DA CIDADE DO NATAL - RN
}

DOI: 1014211/regepe.v5i2.342

Artigo recebido em: 11/01/2016 Artigo aprovado em:07/06/2016

\begin{abstract}
Ana Eliza Galvão Cortez - Universidade Federal do Rio Grande do Norte - UFRN ${ }^{1}$
Thaís Barbosa Ferreira - Serviço Nacional de Aprendizagem Comercial - SENAC ${ }^{2}$ Cristiane de Melo Ferreira - Faculdade Metropolitana de Ciências e Tecnologia - FAMEC ${ }^{3}$ Afrânio Galdino Araújo - Universidade Federal do Rio Grande do Norte - UFRN ${ }^{4}$
\end{abstract}

Resumo: Este estudo tem como objetivo geral compreender a influência dos aspectos cognitivos e afetivos nas trajetórias de mulheres empreendedoras na cidade do Natal - Rio Grande do Norte. Norteia-se pelo framework proposto por Nassif, Ghobril e Silva (2010), que considera a dinamicidade do processo empreendedor ao contemplar fatores como características pessoais, sociológicas e ambientais e as diferentes fases pelas quais passa uma organização. Julgou-se oportuno a realização de um estudo qualitativo e para viabilizar a consecução dos objetivos, utilizou-se o método da história oral temática. A pesquisa foi desenvolvida com dez mulheres empreendedoras da cidade do Natal - RN, que estão à frente de empreendimentos de três anos e meio a 30 anos de existência. A coleta dos dados foi realizada por meio de entrevista semiestruturada, transcrita e analisada utilizando a análise de conteúdo. Os resultados apontam que os aspectos afetivos têm significativa e constante relevância nas ações das empreendedoras em todas as fases de seus empreendimentos e os aspectos cognitivos tornam-se mais influentes à medida que os empreendimentos crescem e se desenvolvem no decorrer da trajetória empreendedora.

Palavras-chave: Empreendedorismo Feminino; Aspectos Cognitivos; Aspectos Afetivos.

\section{COGNITION AND AFFECTIVITY IN ENTREPRENEURIAL CAREERS OF WOMEN IN THE CITY OF NATAL - RN}

Abstract: This study aimed to understand the influence of cognitive and affective aspects in women entrepreneurs' trajectories in the city of Natal - Rio Grande do Norte. The study is situated under the framework proposed by Nassif, Ghobril and

\footnotetext{
1 Endereço: Rua Dr. João Dutra, 1899, apto 1401, Tirol, Natal - RN, CEP: 59015-400. E-mail: anigalvao@hotmail.com

${ }^{2}$ E-mail: thaisufrn@yahoo.com.br

${ }^{3}$ E-mail: crismlferreira@hotmail.com

${ }^{4}$ E-mail: afranioga@gmail.com
}

CORTEZ, A. E. G.; FERREIRA, T. B.; FERREIRA, C. de M.; ARAÚJO, A. G. Cognição e afetividade nas trajetórias empreendedoras das mulheres da cidade do Natal - RN. Revista de Empreendedorismo e Gestão de Pequenas Empresas, v.5, n.2, 2016. 
Silva (2010), which considers the dynamics of the entrepreneurial process considering factors such as personal, sociological and environmental characteristics and the different stages of an organization. It was deemed appropriate to conduct a qualitative study and to facilitate the achievement of its goals, the method of oral history was used. The research was conducted with ten women entrepreneurs, from the city of Natal - RN, who have had their enterprises from three and a half years to thirty years. Data collection was conducted through semi-structured interview that was transcribed and analyzed using content analysis. The results showed that the affective aspects have significant and constant relevance in the actions of entrepreneurs at every stage of their enterprises and the cognitive aspects become more influential as the projects grow and develop in the course of the entrepreneurial path.

Keywords: Women's Entrepreneurship; Cognitive Aspects; Affective Aspects.

\section{Introdução}

O cenário econômico atual aponta para uma crescente escassez de empregos tradicionais, o que faz com que os indivíduos busquem cada vez mais, novas carreiras para se manterem economicamente ativos. Nesse contexto, as ações empreendedoras vêm crescendo em decorrência tanto do caráter involuntário, provocado pela necessidade de renda após um processo de demissão, quanto por aspectos intrínsecos do indivíduo como, por exemplo, a insatisfação com a carreira anterior, o desejo de estar no controle do próprio negócio e o anseio de conciliar o trabalho e a família.

O empreendedorismo vem sendo explorado em diversas pesquisas, haja vista o papel que desempenha na economia e no desenvolvimento de regiões e países (VITA; MARI; POGESSI, 2014; ROCHA; FREITAS, 2014). Os empreendedores são os principais atores nesse processo, variam largamente em suas características e são diretamente influenciados pelo ambiente no qual atuam (SILVA et al., 2013).

De acordo com o que apontam Vidigal e Nassif (2013), aspectos cognitivos e afetivos exercem influências nas ações dos empreendedores, visto que correspondem a aspectos que interferem na geração de ideias e reconhecimento de

CORTEZ, A. E. G.; FERREIRA, T. B.; FERREIRA, C. de M.; ARAÚJO, A. G. Cognição e afetividade nas trajetórias empreendedoras das mulheres da cidade do Natal - RN. Revista de Empreendedorismo e Gestão de Pequenas Empresas, v.5, n.2, 2016. 
oportunidades, e aos sentimentos que os indivíduos experimentam e alimentam ao longo de suas vidas.

Nessa linha, o presente estudo tem como objetivo geral compreender a influência dos aspectos cognitivos e afetivos nas trajetórias de mulheres empreendedoras na cidade do Natal, Rio Grande do Norte. Para tal, traçaram-se os seguintes objetivos específicos: a) identificar as influências e motivações das mulheres empreendedoras da cidade do Natal-RN; b) identificar os aspectos cognitivos e afetivos presentes nas ações de mulheres empreendedoras; e c) analisar os aspectos cognitivos e afetivos identificados, considerando o fator tempo e ambiente.

Para atingir os objetivos propostos, este trabalho norteia-se pelo framework proposto por Nassif, Ghobril e Silva (2010) e pela pesquisa realizada com seis empreendedores em estudo posterior (VIDIGAL; NASSIF, 2013). Para tanto, optouse por analisar os referidos aspectos em mulheres empreendedoras, por ser essa uma abordagem que vem ganhando relevância nos últimos anos. Tal importância desperta o interesse pela realização desta pesquisa que busca responder à seguinte questão: Como se dá a influência dos aspectos afetivos e cognitivos nas trajetórias de mulheres empreendedoras da cidade do Natal-RN?

Nesse âmbito, a pesquisa do projeto GEM (2014) (Global Entrepreneurship Monitor), que tem como objetivo compreender o papel do empreendedorismo no desenvolvimento econômico dos países, aponta que em 2014, no Brasil, o percentual de mulheres à frente de negócios em estágio estabelecido foi de $45 \%$ e de homens 55\%. Tem-se o mesmo índice para a região Nordeste, o que reflete um equilíbrio quanto ao exercício da atividade empreendedora de homens e mulheres no país. Ainda assim, sabe-se que homens e mulheres podem ser diferentes em aspectos como comportamento, características, influências e motivações, o que pode interferir no desenvolvimento, nos modelos de gestão e na competitividade das empresas.

Os estudos sobre empreendedorismo feminino abordam questões sobre o conflito trabalho-família (STROBINO; TEIXEIRA, 2014), o processo de criação de empresas por mulheres (MACHADO et al., 2003), os problemas encontrados ao longo da trajetória empreendedora (ALPERSTEDT; FERREIRA; SERAFIM, 2014), a 
subjetividade das mulheres empreendedoras (FERREIRA; NOGUEIRA, 2013), o perfil das empreendedoras e o planejamento estratégico (TAKAHASHI; GRAEFF; TEIXEIRA, 2006), o perfil e as características das empreendedoras (MARTINS et al., 2010), entre outros estudos, que geralmente relatam as relações que permeiam a vida pessoal e profissional das mulheres.

O estudo torna-se importante quando se considera que o empreendedorismo feminino é um importante motor de crescimento econômico e que de modo geral, a análise de suas características pode ser útil no desenvolvimento de políticas relacionadas à atividade empreendedora e, consequentemente, na compreensão da competitividade e potencial de crescimento de uma região. Outra consideração é que naturalmente a atividade empreendedora já é dotada de entraves e dificuldades. Entretanto, as mulheres enfrentam dificuldades extras quando passam a ter que equilibrar as exigências do negócio com as relações com os filhos, casa e outros dependentes, o que desperta o interesse pelo conhecimento de quais habilidades e competências estão presentes nos modos como elas lidam com essas questões.

Para chegar ao objetivo proposto, são tecidas considerações sobre o empreendedorismo feminino e sobre os aspectos afetivos e cognitivos na atividade empreendedora. Na Metodologia, estão apresentados os delineamentos da pesquisa realizada com dez empreendedoras da cidade de Natal-RN. O tópico Análise dos Resultados traz a discussão sobre a investigação e por fim, as Considerações Finais apresentam aspectos relevantes sobre todo o processo envolvido na pesquisa.

\section{Empreendedorismo Feminino}

O debate geral sobre o empreendedorismo feminino não remete apenas ao ingresso da mulher no mercado de trabalho. Reflete, na verdade, uma alteração social em grandes proporções, que resulta em transformações nas relações familiares, nas expectativas de vida e nas demandas por serviços públicos (GOMES, 2004).

Para muitas mulheres, o caminho do empreendedorismo representa a sua única estratégia de sobrevivência. É o caso, por exemplo, de mulheres que imigram 
de regiões subdesenvolvidas para economias desenvolvidas e passam a lidar com questões não só de gênero, mas também de etnia e veem na ação empreendedora uma única forma de se sobressaírem. Para Vita, Mari e Poggesi (2014), essa intersecção entre gênero e origem étnica também pode ser vista como uma ajuda na criação de novas identidades empresariais que podem favorecer a criatividade e inovação Com base na literatura sobre empreendedorismo, em particular o feminino, é possível perceber a diversidade de motivações e de características presentes nas ações de mulheres empreendedoras. Os estudos demonstram a relevância de se compreender essa particularidade em virtude do representativo crescimento das mulheres no mercado empreendedor e, em sua grande maioria, incidem sobre aspectos peculiares e subjetivos delas (FERREIRA; NOGUEIRA, 2013; LINDO et al., 2007; STROBINO; TEIXEIRA, 2014).

Entre os estudos que norteiam este trabalho, Powell e Eddleston (2013) observaram que a sinergia nas relações trabalho-família, enfatizadas no enriquecimento da afetividade, do apoio e do instrumental (habilidades e comportamentos transferidos) oferecidos nessas relações, pode ser mais benéfica para as mulheres empreendedoras do que para os homens.

Nesse sentido, como muitas vezes elas têm menos acesso a recursos estratégicos (financiamentos, por exemplo), em decorrência de inúmeros motivos, tais como discriminação e dependência do marido, os recursos que elas adquirem no domínio da família tornam-se mais significativos para o sucesso de suas empresas. Os autores acrescentam que a ênfase de mulheres empreendedoras nessa sinergia pode ocorrer em virtude do papel social do gênero masculino que incentiva a independência e autonomia (POWELL; EDDLESTON, 2013).

Os autores Ferreira e Nogueira (2013) apontam para a inseparabilidade das questões de gênero e da atividade empreendedora com relação às questões sociais e às significações no plano individual. Para eles, tanto o ser mulher, quanto o ser empreendedora são produções sociais configuradas a partir dos significados atribuídos pelo próprio indivíduo. Para os autores, a configuração subjetiva do empreendedorismo para as mulheres está embasada nos sentidos subjetivos associados às suas trajetórias, ao contexto atual e à cultura que envolve a atividade desenvolvida. Outra consideração dos autores é que a emoção está na base dos 
processos de pensamento e, portanto, não há que se pensar em empreendedorismo sem considerar a emoção.

Em pesquisa sobre as competências empresariais que caracterizam as mulheres empreendedoras da região Sudeste do Brasil, Nassif et al. (2012) também evidenciam a emoção como complementar e interdependente do aspecto afetivo, visto que todas as mulheres entrevistadas relataram elementos emocionais presentes em seus contextos.

Gomes (2004) evidencia a escassez de investigações sobre o tema e ressalta que o desenvolvimento de mais pesquisas poderá fazer mais pelas mulheres empreendedoras. No Brasil, nos principais eventos de pesquisa em Administração, ainda são poucas as pesquisas que discutem sobre 0 empreendedorismo feminino. Encontram-se em torno de 2 a 3 trabalhos por ano (FERREIRA; NOGUEIRA, 2013).

Vita, Mari e Poggesi (2014) trazem uma revisão sistemática da literatura sobre o tema a partir do ano 2000 e identificam duas áreas atuais que se destacam como desafiadores para futuras pesquisas: a) o papel do empreendedorismo feminino em países em desenvolvimento; e b) a relevância de mulheres empreendedoras imigrantes em países desenvolvidos.

Vale (2014), em análise às origens e evolução das diferentes concepções teóricas sobre o empreendedor, enfatiza a necessidade de caminhar em direção a concepções mais integradas, capazes de associar atributos individuais com observações sobre o contexto ou estrutura social. Para a autora, muitos dos recursos necessários à construção dos empreendimentos encontram-se enraizados em estruturas de relacionamentos e a partir dos laços com diferentes grupos sociais, é possível obter informações sobre oportunidades de negócios, identificar possíveis parcerias, acessar recursos valiosos, chegar a novos clientes, etc.

Dito isto, tem-se o modelo de Nassif, Ghobril e Silva (2010) que busca compreender a influência dos aspectos cognitivos e afetivos nas ações de empreendedores, considerando a dinamicidade do processo empreendedor ao contemplar fatores, como características pessoais, sociológicas e ambientais e as diferentes fases por que passa uma organização. Os autores preocuparam-se com as relações entre as estruturas individuais e sociais que envolvem o processo de 
empreender, sendo este um importante modelo para análise da ação empreendedora. O tópico seguinte traz a explicação do referido modelo.

\section{Aspectos Cognitivos e Afetivos da Ação Empreendedora}

É bem verdade que os novos arranjos produtivos e econômicos trouxeram mudanças para as organizações e também refletiram na manutenção dos empregos formais. A questão da empregabilidade passou a estar cada vez mais conectada ao desenvolvimento de competências por parte do indivíduo (BITENCOURT; BARBOSA, 2010).

As abordagens contemporâneas atribuem aos empreendedores o papel de atores relacionais, que constroem ou desenvolvem oportunidades de negócios por meio de seus recursos pessoais e sociais, que munidos de suas habilidades e motivações, atuam num ambiente incerto (MACHADO; NASSIF, 2014).

Nessa perspectiva, o tema competência tem sido amplamente discutido, devido ao fato de ser peça chave para o desenvolvimento empresarial e consequente alcance de resultados satisfatórios. Drejer (2000) aponta para o fato das competências serem o melhor caminho para explicar a competitividade de uma empresa e para entender, por exemplo, como algumas empresas conseguem alcançar melhor desempenho do que outras, mesmo apresentando as mesmas características funcionais.

Dito isto, percebe-se que uma análise sobre o processo de empreender e as competências do empreendedor deve considerar tanto o empreendedor, tido como o principal ator, quanto $o$ ambiente e as relações dinâmicas e complexas que o caracterizam.

Nesse sentido, o presente estudo está pautado numa perspectiva que trata os aspectos relacionados ao tema competências como algo que vai além da simples qualificação, e corrobora com Zarifian (2001), quando o autor relaciona competências à capacidade do indivíduo de tomar suas próprias iniciativas, ter controle e aprender com as situações vivenciadas nos constantes cenários de mudanças, ser reconhecido pelos outros e ser responsável por suas ações. 
Dessa forma, tendo em vista as diferentes abordagens para o tema competências, este estudo aborda essa temática considerando a ação como aspecto principal e embasando-se em autores clássicos citados por Bitencourt e Barbosa (2010), que trazem em seus conceitos, termos que ilustram a perspectiva adotada: "atitudes relevantes", "conjunto de conhecimentos, habilidades e atitudes interdependentes", “comportamentos observáveis", “conhecimentos, habilidades e formas de atuar", "aspectos intelectuais inatos e adquiridos, capacidades, experiência e maturidade", "assumir responsabilidades", "práticas do cotidiano", "saber agir responsável e reconhecido", "habilidades de comunicação" (SPARROW; BOGNANNO, 1994; DURAND, 1998; CRAVINO, 1997; RUAS, 1999; MOSCOVICI, 1994; LE BOTERF, 1997; PERRENOUD, 1998; FLEURY; FLEURY, 2000; DAVIS, 2000) exercidos em contextos precisos (ZARIFIAN, 2001).

O modelo de Nassif, Ghobril e Silva (2010), que tem como base o esquema interativo das competências do empreendedor a partir de relatos de trajetórias empresariais em pequenas empresas (NASSIF et al., 2004), concentra-se nos atributos pessoais do empreendedor ao abordar os aspectos cognitivos e afetivos presentes nas suas ações. Ele permite uma análise dinâmica da evolução destes atributos no decorrer do percurso do empreendimento e sua interação com os elementos do ambiente (Figura 1).

\section{FIGURA 1 - DINÂMICA DO PROCESSO EMPREENDEDOR.}

Importância

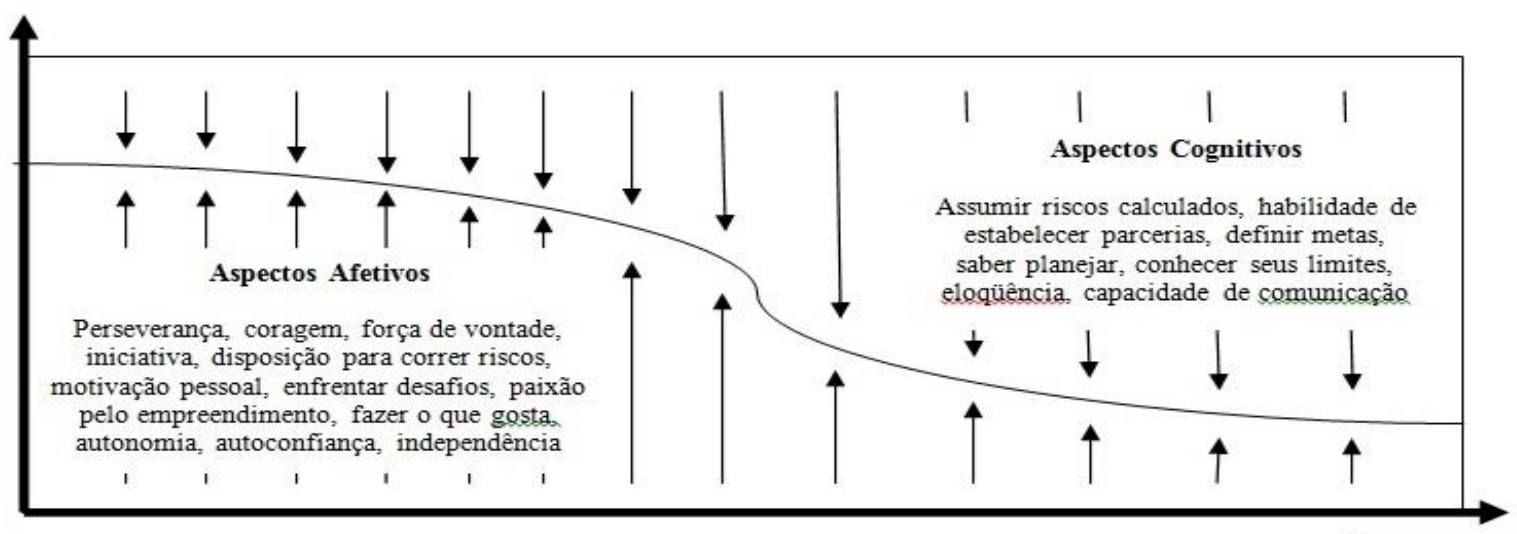

FONTE: Nassif, Ghobril e Silva (2010). 
A cognição está intimamente relacionada ao modo como os indivíduos reconhecem, organizam e processam as informações e guiam suas ações (BROEK; VANDERHEYDEN; COOLS, 2003). A estrutura cognitiva auxilia os indivíduos nas interpretações do passado e presente, orientando-os para o futuro (BASTOS et al., 2011). Na ação empreendedora, os aspectos cognitivos são vistos como modelos mentais simplificados para conectar informações que ajudam a identificar e desenvolver novas oportunidades, bem como para reunir os recursos necessários à construção e ao crescimento de uma empresa (MITCHEL et al., 2002).

Como uma concepção subjetiva do indivíduo e/ou de sua relação com o ambiente, a cognição pode ser influenciada pela memória, pela experiência acumulada, pelo conhecimento e habilidade específica sobre determinada área, pelo acesso e posse de recursos, etc. No modelo em estudo, são aspectos cognitivos do empreendedor: assumir riscos calculados, a habilidade de estabelecer parcerias, a ação de definir metas, o saber planejar, o conhecimento dos limites, a eloquência e a capacidade de comunicação (Figura 1).

Já a afetividade refere-se aos sentimentos que os indivíduos experimentam ao longo de suas vidas. A vertente da psicologia nos estudos sobre empreendedorismo, introduzida por McClelland $(1971,1972)$, aponta para os valores e motivações humanas como fatores que levam o homem a explorar oportunidades. Para o autor, é a necessidade de realização que faz com que os indivíduos canalizem energia na busca de atividades empreendedoras. $O$ autor também ressalta que a estrutura motivacional pode ser distinta, no entanto, algumas características como audácia, liderança, persistência e coragem para assumir riscos são comuns à grande maioria dos empreendedores.

Vidigal e Nassif (2013) trazem a percepção de que a afetividade influencia a ação empreendedora tanto de forma positiva, quanto de forma negativa. Segundo os autores, a afetividade traz efeitos positivos quando os empreendedores carregam suas ações de entusiasmo e persuasão, e negativos quando, movidos pela paixão, perdem a capacidade de avaliar cuidadosamente as ideias e agem sem planejamento.

Essa percepção conduz à relevância do domínio e controle das emoções dentro das organizações, visto que pessoas emocionalmente competentes possuem 
maior probabilidade de dominar os hábitos mentais e lidarem com seus próprios sentimentos, trabalhando-os em favor de suas metas, além de tomarem decisões assertivas sobre suas vidas, de forma a se relacionarem melhor com as pessoas.

Em Nassif, Ghobril e Silva (2010) e Nassif et al. (2004), a afetividade do empreendedor abrange os seguintes aspectos: perseverança, coragem, força de vontade, iniciativa, disposição para correr riscos, motivação pessoal, enfrentar desafios, paixão pelo empreendimento, fazer o que gosta, autonomia, autoconfiança e independência (Figura 1).

No modelo apresentado, sugere-se que variações nas dimensões afetivas e cognitivas dos empreendedores ocorrem na dinâmica do processo empreendedor e exercem influência nas ações, a partir da fase de implantação do negócio e em toda a sua evolução. Considera-se que, tanto os atributos pessoais, quanto os fatores ambientais irão influenciar o andamento do negócio em cada etapa. Ressalta-se que fatores ambientais também incluem fatores sociológicos, tais como modelos, responsabilidades familiares, o trade-off entre a experiência que vem com a idade e o otimismo e energia da juventude, e os contatos de relações pessoais (NASSIF; GHOBRIL; SILVA, 2010).

Os estudos de Nassif, Ghobril e Silva (2010) mostraram que, embora estejam fragmentados na teoria existente, os aspectos cognitivos e afetivos não estão separados na prática. Outro fato interessante foi a constatação da frequência e intensidade das competências afetivas do dia a dia dos empreendedores, mesmo não sendo tão abordadas na literatura quanto as competências cognitivas. A pesquisa ainda levantou a importância do "saber ser", embebido em questões do cotidiano dos empreendedores e ressaltou que a dissociação das competências afetivas e cognitivas pode trazer resultados insatisfatórios.

Nassif et al. (2012) trazem um estudo com mulheres empreendedoras do sudeste do Brasil, que enfrentam limitações financeiras nos desafios do dia a dia de seus empreendimentos. Para tanto, foram estabelecidas três categorias: a) fatores decisivos na abertura de um negócio; b) desafios e obstáculos na carreira empreendedora, e c) competências desenvolvidas e em desenvolvimento durante a trajetória. Os resultados do estudo apontam que os aspectos afetivos são uma parte 
essencial da cultura brasileira e que novos estudos com mulheres empreendedoras devem ser realizados e aprofundados.

\section{Procedimentos Metodológicos}

O empreendedorismo vem se constituindo como importante área de ensino e pesquisa em administração e, embora a sua fundamentação teórica seja conhecida já na década de 1950 com os trabalhos de Schumpeter (1954), a pesquisa empírica surge somente no final do século $\mathrm{XX}$, incluindo múltiplos aspectos como inovação, criatividade, liderança, cultura, visão de futuro, valores e crenças (GIL; SILVA, 2015). As ações decorrentes destes aspectos são reflexos dos modos como os sujeitos vivenciam e interpretam a realidade e tornam-se, portanto, melhor compreendidos quando estudados sob o ponto de vista dos seus atores.

Nessa esteira, o propósito desta pesquisa é o de compreender a influência dos aspectos cognitivos e afetivos nas ações de mulheres empreendedoras da cidade do Natal-RN. Para tal, julgou-se oportuno a realização de um estudo qualitativo do universo do empreendedorismo feminino, norteado pelas abordagens que tratam dos aspectos cognitivos e afetivos da ação empreendedora, sintetizadas no modelo de Nassif, Ghobril e Silva (2010), que serviu como referencial para os aspectos que embasaram a criação de categorias. Isso não excluiu a possibilidade do surgimento de novos aspectos, que foram sugeridos aos existentes, e outros dados relevantes.

Tendo em vista o objetivo geral desta pesquisa, escolheu-se um método que possibilitasse uma aproximação amistosa, proporcionando empatia e a descoberta de singularidades das entrevistadas. Uma vez que todo conhecimento, científico ou não, tem como base primária a fonte oral, sendo a fonte escrita a materialização daquilo que foi dito (BRETAS, 2000), o método da história oral foi o escolhido. Assim, as trajetórias das empresas pesquisadas puderam ser conhecidas não pelos documentos escritos apresentados, mas pelas versões orais de quem protagonizou tais trajetórias (ALBERTI, 2004). 
O ato de contar história é uma capacidade ampla que independe de fatores educacionais. Jovchelovitch e Bauer (2012) afirmam que o entrevistado traz à tona as memórias de fatos que aconteceram, tentam organizar uma sequência para suas experiências e possíveis explicações. A história oral dá voz a segmentos específicos e permite a apreensão de significados não explícitos nas fontes escritas, mas que surgem a partir de entonações, de momentos de silêncio nas narrativas contadas e na própria narrativa. Ouvir uma história permite ao pesquisador perceber sensações e sentimentos relacionados à situação contada (PERAZZO; BASSI, 2007).

Dependendo do conteúdo estudado na história oral, ela pode ser explorada de três formas distintas: 1) história oral temática, quando o entrevistado é levado a narrar sua história direcionando-a para uma determinada temática; 2) história oral de vida, quando o entrevistado narra sua trajetória de vida; e 3) tradição oral, quando o entrevistado narra fatos sobre os quais ele detém informações ou presenciou (BRETAS, 2000). Devido às características deste estudo, a modalidade história oral temática foi a escolhida.

Como método de coleta de dados, foram realizadas entrevistas semiestruturadas com dez empreendedoras da cidade do Natal- RN. Foram consideradas mulheres à frente de empreendimentos já estabelecidos, ou seja, com mais de três anos e meio de existência, conforme verificado em Vidigal e Nassif (2013). No entanto, é preciso ressaltar que elas foram selecionadas de acordo com o nível esperado de contribuição para a pesquisa, sendo, portanto, uma amostragem teórica.

Segundo Flick (2009) esse tipo de amostragem não se baseia em critérios e técnicas usuais de amostragem estatística e o seu tamanho não é definido previamente. Foram escolhidas mulheres que estão à frente de seus negócios, de três anos e meio a 30 anos. Essa escolha garante um melhor aproveitamento do modelo, que considera variações nos aspectos cognitivos e afetivos nas ações dos empreendedores, tanto em função do dinamismo do ambiente, quanto das diferentes fases por que passa uma empresa.

Em uma entrevista semiestruturada há um script incompleto, o pesquisador pode ter preparado algumas perguntas com antecedência, mas pode haver necessidade de improvisação (MYERS; NEWMAN, 2007). O script e as 
improvisações foram utilizados com o intuito de que os aspectos afetivos e cognitivos fossem evidenciados e narrados quando questionadas sobre suas experiências enquanto empreendedoras (NASSIF; GHOBRIL; SILVA, 2010).

Antes da realização de cada entrevista, os objetivos da pesquisa foram explicados e foi assinado um Termo de Consentimento Livre e Esclarecido, para que todas as informações coletadas pudessem ser utilizadas nesta pesquisa. Optou-se por manter os nomes das entrevistadas e os de suas respectivas empresas em sigilo e então, para fins de análise, elas passaram a serem identificadas por E1, E2, E3, E4, E5, E6, E7, E8, E9 e E10.

Os dados coletados nas entrevistas foram transcritos, organizados e categorizados com base nos aspectos trazidos no modelo de Nassif, Ghobril e Silva (2010). Para a análise desses dados, foi escolhido o método de análise de conteúdo. A escolha justifica-se pelo fato de o método ter credibilidade acadêmica e pela expansão do seu uso em diversas áreas (BAUER, 2002; DELLANGELO; SILVA, 2005). Para a categorização dos dados foi escolhida a análise temática, pois permite que, de acordo com o problema pesquisado, temas sejam extraídos do texto, isolados e classificados e, a partir das suas análises, tragam sentidos para o objeto pesquisado (DELLANGELO; SILVA, 2005).

\section{Análise dos Resultados}

Esta seção traz a análise das informações coletadas durante as entrevistas. Após uma breve caracterização do perfil das entrevistadas, os aspectos afetivos e cognitivos identificados foram analisados em consonância com os construtos utilizados no modelo teórico.

Foram entrevistadas dez mulheres de diferentes idades, à frente de empreendimentos que variam de três anos e meio a 30 anos de existência, a fim de abranger e possivelmente equilibrar as diferentes percepções, considerando que a maturidade e a experiência influenciam os aspectos em estudo.

Quatro mulheres têm idade entre 26 e 36 anos, três estão entre 37 e 47 anos e outras três estão entre 48 e 58 anos de idade. No que tange o tempo de 
existência dos empreendimentos, três deles estão no período de existência de três anos e meio a dez anos, quatro estão no período compreendido de 11 a 20 anos de existência e três estão entre 21 e 30 anos de existência.

\section{Influências e Motivações das Mulheres Empreendedoras da Cidade de Natal- RN}

As mulheres pesquisadas neste estudo foram figuras principais quando da decisão de iniciarem seus empreendimentos e sofreram influências dos ambientes nos quais estavam inseridas (SILVA et al., 2013). Por meio de suas habilidades e motivações, construíram e desenvolveram suas empresas (MACHADO; NASSIF, 2014).

Das dez empreendedoras, oito abriram seus empreendimentos a partir da junção do desejo de iniciar ou continuar exercendo determinada atividade e a identificação de oportunidades para alcançarem esse propósito. Duas empreendedoras relataram que o negócio surgiu a partir da identificação de oportunidades no mercado. Ambas as situações podem ser percebidas nos trechos a seguir:

E eu sempre gostei de trabalhar nesse ramo de beleza, eu sempre fui apaixonada por salão de beleza [...] aí fiquei pensando "por que não começar na área da beleza?". Só que assim... É... Eu não sabia aonde começar... Aí eu fui num salão de beleza, me informei com uma... uma profissional da área, onde eu poderia fazer um curso. Aí ela me indicou o SENAC, eu fui, fiz um curso durante um ano e já comecei a trabalhar na área. (E3)

Foi quando abriu o hospital. Então, bom! Eu morava aqui, aqui era minha casa. Talvez, um café... uma coisa assim. Então, abri como um café. (E7)

Desde sempre senti afinidade com cosméticos, e interesse por questões relacionadas a beleza. Em um certo momento, decidi que essa minha afinidade, poderia se transformar em uma profissão, o fato de ser algo que já me interessava, podia gerar uma atividade profissional prazerosa para se dedicar. (E10)

A relação entre gênero e família esteve presente nos discursos das empreendedoras, principalmente ao falarem sobre o início de suas trajetórias. 
Powell e Eddleston (2013) afirmam que as relações trabalho-família podem ser mais benéficas para as mulheres empreendedoras do que para os homens. A falta ou o restrito acesso a recursos formais, como no caso de financiamentos bancários, por exemplo, ocasionados, muitas vezes, por questões de gênero, como discriminação ou dependência financeira do marido ou dos pais, estimula que esse suporte parta de suas próprias famílias. Isso contribui com o sucesso de suas empresas e pode ser constatado nos trechos a seguir:

Eu tive a oportunidade do meu ex-marido me dar uma força, de aparecer a oportunidade de eu comprar uma agência, do ponto, que era lindo! A loja... aí começou linda! (E1)

O antigo sócio confidenciou que tava muito cansado, tava precisando de... de... injeção de gente nova, tava precisando de dinheiro pra manter a sociedade e quando eu saí de lá meu pai olhou pra mim e disse: "e aí, você ainda quer botar a agência de viagem? Que tal a gente comprar essa? Quando a gente chegar, a gente vier, vem!" Eu disse: "Uma boa. Vamos!" (E2)

A gente dividia muito a responsabilidade de cada de setor de cada uma ficava responsável por alguma coisa, e sempre fluía muito bem! E aí, um tempo veio realmente, assim... ajuda financeira, cada uma entrou com sua parte, eu como era muito nova, foi minha mãe que entrou com a minha parte. (E5)

Os valores dos indivíduos também são considerados no modelo em estudo, pois são entendidos como padrões que influenciam no julgamento e seleção entre modelos de comportamento alternativos e são fortemente influenciados pela família, educação e religião (NASSIF; GHOBRIL; SILVA, 2010). Por serem abstratos e mais constantes ao longo do tempo, eles não são observados como mutáveis na trajetória empreendedora. As empreendedoras mencionam em diversos momentos valores como honestidade, lealdade, sinceridade, humildade e simplicidade em suas ações. Importante notar que as entrevistas também evidenciaram a crença religiosa.

Os conceitos de competência que embasam teoricamente este trabalho trazem a ação como uma das ênfases principais de suas abordagens (SPARROW; BOGNANNO, 1994; DURAND, 1998; CRAVINO, 1997; RUAS, 1999; MOSCOVICI, 1994; LE BOTERF, 1997; PERRENOUD, 1998; FLEURY; FLEURY, 2000; DAVIS, 2000). O modelo escolhido aborda os aspectos cognitivos e afetivos presentes 
nessas ações do empreendedor, considerando sua importância no decorrer do tempo e sua interação com os elementos do ambiente (NASSIF; GHOBRIL; SILVA, 2010).

Os tópicos seguintes trazem dois quadros comparativos e reflexões sobre tais aspectos identificados nas ações das empreendedoras pesquisadas na fase inicial e de estabelecimento de cada empreendimento.

\section{Aspectos Cognitivos da Ação Empreendedora Feminina na Fase Inicial e de Estabelecimento do Empreendimento}

Conforme Broek, Vanderheyden e Cools (2003), a cognição está intimamente relacionada ao modo como os indivíduos reconhecem, organizam e processam as informações e guiam suas ações. Os aspectos cognitivos foram verificados nas trajetórias narradas em situações que descrevem experiências, busca por conhecimento e habilidade específica e modelos de gestão.

O Quadro 1 traz as competências identificadas, separadas por meio de duas colunas, as quais referem-se à fase inicial $(\mathrm{FI})$ e ao período a partir de três anos e meio de existência, ou seja, a empresa estabelecida (E).

QUADRO 1 - ASPECTOS COGNITIVOS IDENTIFICADOS NAS MULHERES EMPREENDEDORAS NA FASE INICIAL E DE ESTABELECIMENTO DO EMPREENDIMENTO.

\begin{tabular}{|c|c|c|c|c|c|c|c|c|c|c|c|c|c|c|c|c|c|c|c|c|}
\hline \multirow{2}{*}{$\begin{array}{l}\text { Aspectos } \\
\text { cognitivos }\end{array}$} & \multicolumn{2}{|c|}{$\mathrm{E} 1$} & \multicolumn{2}{|c|}{ E2 } & \multicolumn{2}{|c|}{ E3 } & \multicolumn{2}{|c|}{$\mathrm{E} 4$} & \multicolumn{2}{|c|}{ E5 } & \multicolumn{2}{|c|}{ E6 } & \multicolumn{2}{|c|}{ E7 } & \multicolumn{2}{|c|}{ E8 } & \multicolumn{2}{|c|}{ E9 } & \multicolumn{2}{|c|}{ E10 } \\
\hline & $\mathrm{FI}$ & $E$ & $\mathrm{FI}$ & $E$ & $\mathrm{FI}$ & $E$ & $\mathrm{FI}$ & $E$ & $\mathrm{FI}$ & $E$ & $\mathrm{FI}$ & $E$ & $\mathrm{FI}$ & $E$ & $\mathrm{FI}$ & $E$ & $\mathrm{FI}$ & $E$ & $\mathrm{FI}$ & $E$ \\
\hline $\begin{array}{l}\text { Assumir } \\
\text { riscos } \\
\text { calculados }\end{array}$ & - & $X$ & - & $X$ & - & $X$ & - & $X$ & - & $X$ & $X$ & $X$ & - & $X$ & X & $X$ & - & $X$ & $X$ & $X$ \\
\hline $\begin{array}{l}\text { Habilidade } \\
\text { de } \\
\text { estabelecer } \\
\text { parcerias }\end{array}$ & $X$ & $X$ & - & $X$ & - & $X$ & $X$ & $X$ & $X$ & $X$ & $X$ & $X$ & - & - & - & $X$ & - & $X$ & - & $X$ \\
\hline $\begin{array}{l}\text { Definir } \\
\text { metas }\end{array}$ & - & $X$ & - & $X$ & - & $X$ & - & $X$ & - & - & - & - & - & - & - & - & - & $X$ & - & - \\
\hline $\begin{array}{l}\text { Saber } \\
\text { planejar }\end{array}$ & - & $X$ & - & $X$ & - & $X$ & - & $\mathrm{X}$ & $X$ & $\mathrm{X}$ & $\mathrm{X}$ & $X$ & - & $\mathrm{X}$ & $X$ & $X$ & - & $X$ & - & - \\
\hline $\begin{array}{l}\text { Conhecer } \\
\text { seus } \\
\text { limites }\end{array}$ & - & $X$ & - & - & $X$ & $X$ & $X$ & $X$ & X & - & $X$ & $X$ & - & - & $X$ & $X$ & - & $X$ & - & - \\
\hline Eloquência & $\mathrm{X}$ & $X$ & $X$ & $\mathrm{X}$ & $\mathrm{X}$ & $X$ & - & $X$ & - & - & - & - & - & - & - & $X$ & - & $X$ & - & - \\
\hline $\begin{array}{l}\text { Capacidad } \\
\text { e de } \\
\text { comunicaç } \\
\text { ão }\end{array}$ & $X$ & $X$ & $X$ & $X$ & $X$ & $X$ & $X$ & $X$ & - & - & - & - & $X$ & $X$ & - & $X$ & $X$ & $X$ & $X$ & $X$ \\
\hline
\end{tabular}

FONTE: Dados da pesquisa (2015).

CORTEZ, A. E. G.; FERREIRA, T. B.; FERREIRA, C. de M.; ARAÚJO, A. G. Cognição e afetividade nas trajetórias empreendedoras das mulheres da cidade do Natal - RN. Revista de Empreendedorismo e Gestão de Pequenas Empresas, v.5, n.2, 2016. 
Em análise do Quadro 1, é possível identificar que as empreendedoras iniciam seus empreendimentos com algumas competências cognitivas sugeridas no modelo e que no decorrer do desenvolvimento das empresas essas competências aumentam ou permanecem. Como exemplo, E1 demonstrou ter habilidade de estabelecer parcerias, capacidade de comunicação e eloquência bem desenvolvidas ao iniciar seu negócio. Após ele já estabelecido (passados três anos e meio), essas competências permaneceram e outras foram desenvolvidas.

Com exceção de E5 e E6, as trajetórias narradas confirmam o proposto por Nassif, Ghobril e Silva (2010), que sugerem o aumento da influência dos aspectos cognitivos na solidificação de um negócio. Verificou-se ainda que os aspectos assumir riscos calculados, saber planejar e definir metas surgiram ou foram intensificados a partir do estabelecimento dos empreendimentos. Esses resultados vão de encontro ao estudo de Vidigal e Nassif (2013), que apontam uma diminuição na preocupação com o planejamento, por parte dos empreendedores, com o passar dos anos.

A estrutura cognitiva auxilia os indivíduos nas interpretações do passado e presente, orientando-os para o futuro (BASTOS et al., 2011). Nos relatos, foi possível identificar que algumas das atitudes das empreendedoras são tomadas com base em situações vivenciadas anteriormente. A memória sobre essas experiências é um traço marcante em seus discursos, uma vez que proporcionam aprendizagem e também influenciam suas ações, como se pode verificar:

Secretaria... dessa parte de técnico administrativo... E... É uma coisa que hoje me ajuda a administrar a escola. Um pouquinho de experiência que me ajudou... Pra coordenar, porque hoje em dia eu faço tudo: de ASG à proprietária. (E6)

Uma vez, eu adolescente, já trabalhava com meu pai e resolvi ficar na praia num domingo e só voltar pra Natal na segunda-feira. Quando eu cheguei, era umas dez horas da segunda-feira, tinha uma carta dele pra mim, em cima da mesa, dizendo que se eu quisesse crescer, eu tinha que ter responsabilidade, que eu era pra ter voltado da praia no domingo... Que na segunda de manhã eu já era pra estar na empresa... (E8)

Ele não falou nada, ele apenas escreveu, e eu tenho essa carta guardada até hoje, porque assim... Ela... pronto... Me marcou. Aí, a partir daí eu 
voltava toda vida da praia no domingo. Segunda-feira, logo cedo, eu estava trabalhando. (E8)

$\mathrm{Na}$ ação empreendedora, os aspectos cognitivos são como modelos mentais simplificados para conectar informações que ajudam a identificar e desenvolver novas oportunidades, bem como para reunir os recursos necessários à construção e ao crescimento de uma empresa (MITCHEL et al., 2002). De fato, essa percepção pode ser verificada com clareza nos seguintes relatos:

\begin{abstract}
Eu trabalho muito a internet como um... eu sei que é a grande concorrência nossa, mas trabalho como aliada. Aqui você descobre tudo, aqui você estuda, aqui você descobre o que tem, o que não tem, o que você pode correr atrás pra poder você acompanhar... Então eu não olho a internet como minha concorrente... sabendo que ela é! Eu puxo dela e sugo dela o que ela pode me oferecer pra eu ficar... competitiva como ela! [...] E eu sou muito de... de ver o lado que eu possa... alguma... alguma coisa que eu possa pegar dali, que eu possa ter oportunidade de crescer. (E1)
\end{abstract}

Eu estudo e trabalho 24 horas, de fato, nada do que eu vejo eu consigo olhar simplesmente e não tentar olhar, ver o que eu estou vendo, transformando ele e aplicando no meu dia-a-dia. Então eu digo... a minha mente, ela está 24 horas em estudo. Eu olhando pra você, alguma coisa que eu olho em você, eu posso tá transformando isso pra colocar no meu dia-a-dia do meu negócio. (E2)

\title{
Aspectos Afetivos da Ação Empreendedora Feminina na Fase Inicial e de Estabelecimento do Empreendimento
}

Em análise do Quadro 2, que segue a mesma formatação utilizada para explicar o Quadro 1, percebe-se uma forte influência dos aspectos afetivos na fase inicial dos empreendimentos, conforme sugere o modelo de Nassif, Ghobril e Silva (2010). No entanto, percebe-se também que essa influência perdura nas etapas seguintes de desenvolvimento das empresas. De acordo com os autores, a dissociação das competências afetivas e cognitivas nas questões do cotidiano dos empreendedores pode trazer resultados insatisfatórios. Depreende-se, portanto, do Quadro 2, que as empreendedoras são fortemente influenciadas pelos aspectos afetivos durante toda a dinâmica do processo empreendedor.

Somando-se isso ao fato de que, também no desenvolvimento de seus empreendimentos, as empreendedoras evoluem em termos de competências 
cognitivas, conforme detalhado no tópico anterior, essa junção entre o aumento da influência dos aspectos cognitivos e a presença dos aspectos afetivos como motivadores de suas ações durante todo o processo, pode ser uma possível explicação para o sucesso desses empreendimentos.

QUADRO 2 - ASPECTOS AFETIVOS IDENTIFICADOS NAS MULHERES EMPREENDEDORAS NA FASE INICIAL E DE ESTABELECIMENTO DO EMPREENDIMENTO.

\begin{tabular}{|c|c|c|c|c|c|c|c|c|c|c|c|c|c|c|c|c|c|c|c|c|}
\hline \multirow{2}{*}{$\begin{array}{l}\text { Aspectos } \\
\text { Afetivos }\end{array}$} & \multicolumn{2}{|c|}{$\mathrm{E} 1$} & \multicolumn{2}{|c|}{ E2 } & \multicolumn{2}{|c|}{ E3 } & \multicolumn{2}{|c|}{ E4 } & \multicolumn{2}{|c|}{ E5 } & \multicolumn{2}{|c|}{ E6 } & \multicolumn{2}{|c|}{ E7 } & \multicolumn{2}{|c|}{ E8 } & \multicolumn{2}{|c|}{ E9 } & \multicolumn{2}{|c|}{ E10 } \\
\hline & $\mathrm{FI}$ & $E$ & $\mathrm{FI}$ & $\mathrm{E}$ & $\mathrm{FI}$ & $E$ & $\mathrm{FI}$ & $E$ & $\mathrm{FI}$ & $E$ & $\mathrm{FI}$ & $E$ & $\mathrm{FI}$ & $E$ & $\mathrm{FI}$ & $E$ & $\mathrm{FI}$ & $E$ & $\mathrm{FI}$ & $E$ \\
\hline Perseverança & $\mathrm{X}$ & $\mathrm{X}$ & $\mathrm{X}$ & $\mathrm{X}$ & - & - & $\mathrm{X}$ & $\mathrm{X}$ & $\mathrm{X}$ & - & - & $\mathrm{X}$ & $\mathrm{X}$ & $\mathrm{X}$ & $\mathrm{X}$ & $\mathrm{X}$ & $\mathrm{X}$ & $\mathrm{X}$ & $\mathrm{X}$ & $\mathrm{X}$ \\
\hline Coragem & $\mathrm{X}$ & $\mathrm{X}$ & $\mathrm{X}$ & - & 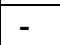 & $\mathrm{X}$ & $\mathrm{X}$ & $\mathrm{X}$ & $\mathrm{X}$ & - & $\mathrm{X}$ & $\mathrm{X}$ & $\mathrm{X}$ & $\mathrm{X}$ & & $\mathrm{X}$ & $\mathrm{X}$ & $\mathrm{X}$ & $\mathrm{X}$ & $\mathrm{X}$ \\
\hline $\begin{array}{l}\text { Força } \\
\text { vonta }\end{array}$ & $\mathrm{X}$ & $\bar{X}$ & $\mathrm{X}$ & $\mathrm{X}$ & - & - & $\mathrm{X}$ & $\mathrm{X}$ & & - & - & - & $\mathrm{X}$ & $\mathrm{X}$ & $\mathrm{X}$ & $\mathrm{X}$ & $\mathrm{X}$ & $X$ & $\mathrm{X}$ & $x$ \\
\hline Inicia & $\mathrm{X}$ & $\mathrm{X}$ & $\mathrm{X}$ & $\mathrm{X}$ & $\mathrm{X}$ & - & $\mathrm{X}$ & $\mathrm{X}$ & $\mathrm{X}$ & $\mathrm{X}$ & - & $\mathrm{X}$ & $\mathrm{X}$ & $\mathrm{X}$ & - & & $\mathrm{X}$ & $\mathrm{X}$ & $\mathrm{X}$ & $\mathrm{X}$ \\
\hline $\begin{array}{l}\text { Dispos } \\
\text { para ce } \\
\text { riscos }\end{array}$ & $\mathrm{X}$ & $\mathrm{X}$ & $\mathrm{X}$ & - & - & $\mathrm{X}$ & $\mathrm{X}$ & $\mathrm{X}$ & & - & $\mathrm{X}$ & $\mathrm{X}$ & $\mathrm{X}$ & $X$ & - & $\mathrm{X}$ & - & - & $x$ & $X$ \\
\hline Motivação & $\mathrm{X}$ & $\mathrm{X}$ & $\mathrm{X}$ & $\mathrm{X}$ & $\mathrm{X}$ & - & $\mathrm{X}$ & $\mathrm{X}$ & $\mathrm{X}$ & - & $x$ & $X$ & $\mathrm{X}$ & $\mathrm{X}$ & - & $\mathrm{x}$ & $\mathrm{X}$ & $x$ & $\mathrm{X}$ & $x$ \\
\hline $\begin{array}{l}\text { Enfre } \\
\text { desaf }\end{array}$ & $\mathrm{X}$ & $\mathrm{x}$ & $X$ & $\mathrm{x}$ & - & $X$ & $x$ & $X$ & - & - & - & - & $X$ & - & - & $\mathrm{x}$ & $X$ & $\mathrm{x}$ & - & - \\
\hline $\begin{array}{l}\text { Paixão pelo } \\
\text { negócio }\end{array}$ & $X$ & $\mathrm{X}$ & & $\mathrm{X}$ & - & - & $\mathrm{X}$ & $x$ & & - & $\mathrm{X}$ & - & & $\mathrm{X}$ & - & $\mathrm{X}$ & $\mathrm{X}$ & $\mathrm{X}$ & $\mathrm{X}$ & $\mathrm{X}$ \\
\hline $\begin{array}{l}\text { Fazer o que } \\
\text { gosta }\end{array}$ & $\mathrm{X}$ & $\mathrm{X}$ & $X$ & $\mathrm{X}$ & $\mathrm{X}$ & $\mathrm{X}$ & $\mathrm{X}$ & $\mathrm{X}$ & $\mathrm{X}$ & - & $\mathrm{X}$ & $\mathrm{X}$ & $X$ & $\mathrm{X}$ & $\mathrm{X}$ & $\mathrm{x}$ & $\mathrm{X}$ & $x$ & $\mathrm{X}$ & $\mathrm{X}$ \\
\hline Autor & - & $>$ & $x$ & $\mathrm{X}$ & - & $>$ & $\mathrm{X}$ & \rangle & X & - & - & - & $x$ & $X$ & - & $\mathrm{X}$ & - & $\mathrm{X}$ & $\mathrm{X}$ & $X$ \\
\hline $\begin{array}{l}\text { Autoconfian } \\
\text { Ça }\end{array}$ & $\mathrm{X}$ & $x$ & $X$ & $X$ & - & $X$ & $x$ & $x$ & - & - & - & $\mathrm{X}$ & $X$ & $\mathrm{X}$ & - & $X$ & - & $x$ & - & $x$ \\
\hline Independência & - & $\mathrm{X}$ & & $\mathrm{X}$ & - & $\mathrm{X}$ & $\mathrm{X}$ & $\mathrm{X}$ & - & - & - & - & $X$ & $\mathrm{X}$ & - & $\mathrm{X}$ & - & - & - & $\mathrm{X}$ \\
\hline
\end{tabular}

FONTE: Dados da pesquisa (2015).

Conforme McClelland $(1971,1972)$, a estrutura motivacional pode ser distinta, mas algumas características como audácia, liderança, persistência e coragem para assumir riscos são identificadas na grande maioria dos empreendedores. No caso específico das empreendedoras entrevistadas, esses aspectos da afetividade, de fato, influenciam suas ações tanto na fase inicial (E2 e E4), quanto na de estabelecimento (E7 e E9), conforme os trechos abaixo:

Sempre lutei pra que tudo desse muito certo. Foram anos difíceis, porque eu não fazia ideia pra onde ia, não sabia o que era uma viagem, como vender uma viagem, como emitir um bilhete, como reservar um bilhete... [...] Mas eu sempre tive um desejo muito grande de tudo. Nada meu era pequeno. E... com muito cuidado, com muita coragem em tudo, mas assim, com muita vontade de realizar e de fazer acontecer. (E2)

CORTEZ, A. E. G.; FERREIRA, T. B.; FERREIRA, C. de M.; ARAÚJO, A. G. Cognição e afetividade nas trajetórias empreendedoras das mulheres da cidade do Natal - RN. Revista de Empreendedorismo e Gestão de Pequenas Empresas, v.5, n.2, 2016. 
Aí, eu peguei e comprei essa casa aqui. Eu demoli a casa e comecei do zero esse... [...] E aí, construí e vim pra cá! $\mathrm{E}$ aqui eu estou há 10 anos, esse ano vai para 11 anos que tô aqui. (E4)

As indicações entre fornecedores faz aumentar o leque de opções, mas mesmo após conquistar alianças é preciso mantê-las com unhas e dentes. (E9)

Eu gosto de... de descobrir algumas coisas. Como um prato quando a gente viaja, aí eu tento... reproduzir. Então, hoje já é... já é... bem legal! [...] Sempre que eu posso, faço! Nunca fiz cursos fora e hoje eu tenho objetivos de fazer isso. (E7)

Conforme apontado no estudo de Vidigal e Nassif (2013), a afetividade pode influenciar a ação empreendedora, tanto de forma positiva, quanto de forma negativa. Para os autores, os efeitos são positivos quando os empreendedores agem movidos pelo entusiasmo e persuasão, e negativos quando movidos pela paixão, pois perdem a capacidade de avaliar suas ideias atenciosamente e agem sem planejamento. Devido à importância que a relação trabalho-família teve e tem nas trajetórias narradas e da forte influência da afetividade nas ações das empreendedoras, conforme mostrado no Quadro 2, em dois casos alguns efeitos negativos foram detectados:

Porque eu comecei um negócio errado. Eu comecei um negócio trazendo as pessoas para dentro do meu salão, querendo formar uma família. E é mentira! Empresa é empresa, família é família! A gente tem que separar! Aí, eu não separava... E aí, as pessoas às vezes dão uma de esperta, eles querem a... se aproveitar mesmo! Da família, né? (E4)

Pra você ter uma ideia, no começo, eu levava minhas funcionárias pro teatro, porque elas nunca tinham ido pro teatro, levava pro cinema, porque nunca tinham ido pro cinema, até... uma me roubar. Aí eu disse "ah, não é bem assim não". A gente pensa que pode [...] ser amiga, mas não é bem assim. (E7)

Esses fatos certamente desencadearam a necessidade de maior planejamento por parte dessas mulheres, o que provavelmente acarretou o desenvolvimento de competências cognitivas. Isso mostra a relevância do domínio e controle das emoções dentro das organizações e corrobora com Nassif, Ghobril e Silva (2010) e Nassif et al. (2004), quando apontam que, embora os aspectos afetivos e cognitivos estejam fragmentados na teoria existente, na prática eles não estão separados. 
Essa relação corrobora com a percepção de Ferreira e Nogueira (2013) sobre a inseparabilidade das questões de gênero e da atividade empreendedora com relação às questões sociais e as significações no plano individual. Os efeitos positivos dos aspectos afetivos foram identificados em todas as entrevistas, quando as empreendedoras demonstraram suas motivações, paixão pelo negócio, coragem, força de vontade, autoconfiança, entre outros aspectos.

\section{Considerações Finais}

Face ao exposto na análise dos resultados, tem-se que o objetivo principal da pesquisa foi atingido. No transcorrer de suas histórias enquanto empreendedoras, tanto nas fases iniciais, quanto nas fases de empresas estabelecidas, as entrevistadas evidenciaram a influência dos aspectos afetivos em suas ações de modo significativo. Suas motivações pessoais, paixão pelo negócio, coragem, força de vontade, iniciativa e autoconfiança, dentre outros aspectos, foram ressaltados em todas as entrevistas.

Também foi identificado que as empreendedoras iniciam suas empresas sob a influência de algumas competências cognitivas sugeridas no modelo, em menor estima do que as afetivas, e que, no decorrer do desenvolvimento de suas empresas, essas competências aumentam ou permanecem. Na solidificação de seus empreendimentos, verificou-se que os aspectos assumir riscos calculados, saber planejar e definir metas surgiram ou foram intensificados.

A realização desta pesquisa confirma a relevância do modelo proposto por Nassif, Ghobril e Silva (2010), tanto com relação aos aspectos cognitivos e afetivos sugeridos, que foram identificados como pertinentes às ações das empreendedoras, quanto à variação desses aspectos no desenvolvimento dos empreendimentos. Os autores sugerem que nas fases iniciais, períodos que envolvem a descoberta e exploração de uma oportunidade, os empreendedores agem motivados principalmente pela afetividade e à medida que os empreendimentos crescem e se desenvolvem, os aspectos cognitivos passam a influenciar mais as ações, em 
virtude de demandas, tais como necessidade de conquistar e manter clientes e se posicionar no mercado.

Diante dessas considerações, ressalta-se que a incapacidade de gestão para compreender as questões que permeiam o desenvolvimento organizacional pode resultar em uma empresa "congelada" em seu atual estágio de evolução e, em última análise, em falha (GREINER, 1972). Dito isso, entende-se que o conceito de empreendedor deve ser relacionado a uma pessoa de ação, isto é: "alguém capaz de realizar, transformar, visualizar oportunidades, sonhar, acreditar, assumir riscos e desafios, agregando recursos e pessoas. Alguém capaz de inserir-se ativamente no seu contexto em busca de mudanças e inovações" (NASSIF; GHOBRIL; SILVA, 2010, p. 189).

Assim como verificado nesse estudo, os autores Nassif, Ghobril e Silva (2010) apontam que, embora estejam fragmentados na teoria existente, os aspectos cognitivos e afetivos não se separam na prática. Para os autores, essa separação pode trazer resultados insatisfatórios. Nessa direção, admitir a emoção como participante do mundo empresarial pode dar ao indivíduo a oportunidade de conhecer a si mesmo e a se emancipar (FERREIRA; NOGUEIRA, 2013). Portanto, reconhecer o tipo de emoção que está na base dos pensamentos, torna mais completo o entendimento das diversas variáveis que envolvem a atividade empreendedora.

A pesquisa também identificou que as empreendedoras da cidade de Natal iniciam suas trajetórias movidas pelo desejo e/ou oportunidade de fazerem o que gostam e se apoiam principalmente nas relações amigo/família. Elas também demonstraram a procura pelo conhecimento técnico e formal. Nas narrativas, foi identificada a busca pela realização de cursos, pelo apoio de órgãos como o SENAC (Serviço Nacional de Aprendizagem Comercial) e o estudo frequente de tendências, mercados e modos de trabalho por meio da internet. Sugere-se que novos estudos sejam realizados a fim de verificar o estudo formal como possível variável do aspecto cognitivo no modelo utilizado.

Uma forma de encontrar resultados mais precisos para a variação na influência dos aspectos cognitivos e afetivos nas ações dos empreendedores em suas trajetórias é acrescentar a perspectiva do ciclo de vida organizacional ao 
modelo. Tal abordagem reconhece que as diferentes fases de um empreendimento demandam mudanças no papel do empreendedor e nas competências necessárias ao desenvolvimento, sucesso e crescimento (CHURCHILL; LEWIS, 1983).

Dessa forma, ao demarcar a trajetória de um empreendedor em acordo com a fase de desenvolvimento do seu empreendimento, torna-se possível a realização de uma análise mais detalhada sobre os aspectos em questão, em virtude da consideração do que é vivenciado por ele naquele momento.

Corroborando com outros autores, sugere-se a realização de estudos longitudinais que destaquem a dinâmica que influencia na construção, transformação e uso de elementos cognitivos no processo empresarial (MALMSTRÖM; JOHANSSON; WINCENT, 2015) e a complexidade das relações entre fatores individuais e ambientais (ARMSTRONG; COOLS; SADLER-SMITH, 2012), visto que o desenvolvimento de um empreendimento é resultado de um processo que ocorre ao longo do tempo (YAMAKAWA; PENG; DEEDS, 2015).

Resultados mais robustos também podem se dar por meio de trabalhos de cunho quantitativo, com a utilização de survey, envolvendo um grande número de participantes e a análise de relações entre variáveis. Outros estudos que relacionem o fator gênero, abordados sob outras perspectivas, tais como a questão cultural ou de regionalidades, podem ser trabalhados.

Com a realização de entrevistas, técnica em que o entrevistador não deve influenciar as respostas dos entrevistados, os aspectos cognitivos e afetivos somente puderam ser identificados através do que ficou explícito no discurso das entrevistadas, sendo essa uma limitação da pesquisa. Além disso, por se tratar de uma pesquisa qualitativa realizada com mulheres que vivenciam um determinado contexto, os resultados das análises não podem ser generalizados.

\section{Referências:}

ALBERTI, V. Manual de história oral. 2. ed. Rio de Janeiro: Editora FGV, 2004.

ALPERSTEDT, G. D.; FERREIRA, J. B.; SERAFIM, M. C. Empreendedorismo feminino: dificuldades relatadas em histórias de vida. Revista de Ciências da Administração, v. 16, n. 40, p. 221-234, 2014. 
ARMSTRONG, S. J.; COOLS, E.; SADLER-SMITH, E. Role of cognitive styles in business and management: Reviewing 40 years of research. International Journal of Management Reviews, v. 14, n. 3, p. 238-262, 2012.

BASTOS, A. V. B.; SOUZA, J. J.; COSTA, V. M. F.; PEIXOTO, A. L. A. A adoção de novas práticas de gestão: explorando o esquema cognitivo dos atores em empresas com diferentes padrões de inovação. Revista de Ciências da Administração, v. 13, n. 31, p. 243-268, 2011.

BAUER, M. W. Análise de conteúdo clássica: uma revisão. In: BAUER, M. W.; GASKELL, G. Tradução de Pedrinho Guareshi. Pesquisa qualitativa com texto, imagem e som: um manual prático. 4. ed. Petrópolis: Vozes, 2002. p. 90-113

BITENCOURT, C. C.; BARBOSA, A. C. Q. Gestão de competências: articulando indivíduos, organizações e sociedade. In: BITENCOURT, C. (Org.) Gestão Contemporânea de Pessoas: novas práticas, conceitos tradicionais. 2. ed. Porto Alegre: Bookman, 2010.

BRETAS, A. C. P. Pesquisa qualitativa e o método da história oral: aspectos conceituais. Acta Paul Enf, v. 13, n. 3, p. 81-91, 2000.

BROEK, V. H.; VANDERHEYDEN, K.; COOLS, E. Individual differences in cognitive styles: development, validation and cross-validation of the cognitive style inventory. [Working Paper]. Vlerick Leuven Gent Management School, 2003.

CHURCHILL, N. C.; LEWIS, V. L. The five stages of small business growth. Harvard Business Review, v. 61, n. 3, p. 1-12, 1983.

CRAVINO, L. Conceptos y herramientas de management. Administración de Desempeño, n. 24, 1997.

DAVIS, L. The work activity briefing: A model for workplace learning and leadership. 2000. Dissertação (Mestrado em Educação). Brisbane, 2000.

DELLANGELO, E. H. L.; SILVA, R. C. Análise de conteúdo e sua aplicação em pesquisa na administração. In: VIEIRA, M. M. F.; ZOUAIN, D. M. (Orgs.). Pesquisa qualitativa em administração: teoria e prática. Rio de Janeiro: FGV, 2005.

DREJER, A. Organizational learning and competence development. The Learning Organization, v. 7, n. 4, p. 206-220, 2000.

DURAND, T. Forms of Incompetence. In: PROCEEDINGS FOURTH INTERNATIONAL CONFERENCE ON COMPETENCE-BASED MANAGEMENT. Proceedings... Oslo: Norwegian School Of Management, 1998.

FERREIRA, J. M.; NOGUEIRA, E. E. S. Mulheres e suas histórias: razão, sensibilidade e subjetividade no empreendedorismo feminino. Revista de Administração Contemporânea, v. 17, n. 4, p. 398-417, 2013.

CORTEZ, A. E. G.; FERREIRA, T. B.; FERREIRA, C. de M.; ARAÚJO, A. G. Cognição e afetividade nas trajetórias empreendedoras das mulheres da cidade do Natal - RN. Revista de Empreendedorismo e Gestão de Pequenas Empresas, v.5, n.2, 2016. 
FLEURY, M.; FLEURY, A. Estratégias empresariais e formação de competências: Um quebra-cabeça caleidoscópio da indústria brasileira. São Paulo: Atlas, 2000.

FLICK, U. Uma Introdução à Pesquisa Qualitativa. 3. ed. Porto Alegre: Bookman, 2009

GEM, GLOBAL ENTREPRENEURSHIP MONITOR. Empreendedorismo no Brasil 2014: relatório executivo. Curitiba: IBQP, 2014

GIL, A. C.; SILVA, S. P. M. O Método Fenomenológico na pesquisa sobre empreendedorismo no Brasil. Revista de Ciências da Administração, v. 17, n. 41, p. 99-113, 2015.

GOMES, A. F. O perfil empreendedor de mulheres que conduzem seu próprio negócio: um estudo na cidade de Vitória da Conquista-BA. Revista Alcance, v. 11, n. 2, p. 207-226, 2004.

GREINER, L. E. Evolution and revolution as organizations grow. Harvard Business Review, v. 50, n. 4, p. 37-46, 1972.

JOVCHELOVITCH, S.; BAUER, M. W. Entrevista narrativa. In: BAUER, M. W.; GASKELL, G. (Org.). Pesquisa qualitativa com texto, imagem e som: um manual prático. Petrópolis: Vozes, 2002. p. 90-113.

LE BOTERF, G. Construire la compétence collective de l'entreprise. GESTIONMONTREAL, v. 22, n. 3, p. 82-85, 1997.

LINDO, M. R.; CARDOSO, P. M.; RODRIGUES, M. E.; WETZEL, U. Vida pessoal e vida profissional: os desafios de equilíbrio para mulheres empreendedoras do Rio de Janeiro. RAC-Eletrônica, v. 1, n. 1, p. 1-15, 2007.

MACHADO, H. P. V.; NASSIF, V. M. J. Réplica - Empreendedores: reflexões sobre concepções históricas e contemporâneas. Revista de Administração Contemporânea, v. 18, n. 6, p. 892-899, 2014.

MACHADO, H. V.; ST-CYR, L.; MIONE, A.; ALVES, M. C. M. O processo de criação de empresas por mulheres. RAE-eletrônica, v. 2, n. 2, p. 1-22, 2003.

MALMSTRÖM, M.; JOHANSSON, J.; WINCENT, J. Cognitive constructions of low-profit and high-profit business models: A repertory grid study of serial entrepreneurs. Entrepreneurship Theory and Practice, v. 39, n. 5, p. 1083-1109, 2015.

MARTINS, C. B.; CRNKOVIC, L. H.; PIZZINATTO, N. K.; MACCARI, E. A. Empreendedorismo feminino: características e perfil de gestão em pequenas e

CORTEZ, A. E. G.; FERREIRA, T. B.; FERREIRA, C. de M.; ARAÚJO, A. G. Cognição e afetividade nas trajetórias empreendedoras das mulheres da cidade do Natal - RN. Revista de Empreendedorismo e Gestão de Pequenas Empresas, v.5, n.2, 2016. 
médias empresas. Revista de Administração da UFSM, v. 3, n. 2, p. 288-302, 2010.

MCCLELLAND, D. C. The achievement motive in economic growth. In: KILBY, P. (Ed.). Entrepreneurship and economic development. New York: The Free Press, 1971. p. 109-122.

A sociedade competitiva. Rio de Janeiro: Expressão e Cultura, 1972.

MITCHELL, R. K.; BUSENITZ, L.; LANT, T.; MCDOUGALL, P. P.; MORSE, E. A.; SMITH, J. B. Toward a theory of entrepreneurial cognition: rethinking the people side of entrepreneurship research. Entrepreneuship Theory \& Practice, v. 27, n. 2, p. 93-104, 2002.

MOSCOVICI, F. Equipes dão certo. Rio de Janeiro: José Olympio Editora, 1994.

MYERS, M. D.; NEWMAN, M. The qualitative interview in IS research: Examining the craft. Information \& Organization, v. 17, n. 1, p. 2-26, 2007.

NASSIF, V. M. J.; GHOBRIL, A. N.; COSTA, A. C. F.; SILVA, N. S. GUARDANI, F. Contribuição para o entendimento das competências do empreendedor: a derivação de um esquema a partir de relatos de trajetórias empresariais em pequenas empresas. In: ENCONTRO ANUAL DA ANPAD, 2004, Rio de Janeiro. Anais... Rio de Janeiro, 2004. 1 CD-ROM.

Women entrepreneurs: Discussion about their competencies. African Journal of Business Management, v. 6, n. 26, p. 7694-7704, 2012.

NASSIF, V. M. J.; GHOBRIL, A. N.; SILVA, N. S. Understanding the entrepreneurial process: a dynamic approach. Brazilian Administration Review, v. 7, n. 2, p. 213226, 2010.

PERAZZO, P. F.; BASSI, C. S. Possibilidades do método de história oral nos estudos em administração. In: ENCONTRO DE ENSINO E PESQUISA EM ADMINISTRAÇÃO E CONTABILIDADE, 1., 2007, Recife. Anais... Recife, 2007.

PERRENOUD, P. Construire des Compétences, est-ce tourner le dos aux savoirs?. Genève: Université de Genève, 1998. Disponível em: <http://www.unige.ch/fapse/SSE/teachers/perrenoud/php_main/php_1998/1998_34.h tml>. Acesso em: 28 jun. 2015.

POWELL, G. N.; EDDLESTON, A. K. Linking family-to-business enrichment and support to entrepreneurial success: Do female and male entrepreneurs experience different outcomes? Journal of Business Venturing, v. 28, n. 2, p. 261-280, 2013.

ROCHA, E. L. C.; FREITAS, A. A. F. Avaliação do ensino de empreendedorismo entre estudantes universitários por meio do perfil empreendedor. Revista de Administração Contemporânea, v. 18, n. 4, p. 465-486, 2014.

CORTEZ, A. E. G.; FERREIRA, T. B.; FERREIRA, C. de M.; ARAÚJO, A. G. Cognição e afetividade nas trajetórias empreendedoras das mulheres da cidade do Natal - RN. Revista de Empreendedorismo e Gestão de Pequenas Empresas, v.5, n.2, 2016. 
RUAS, R. Competências gerenciais e aprendizagem nas organizações: uma relação de futuro? In: SEMINÁRIO INTERNACIONAL DE COMPETITIVIDADE BASEADA NO CONHECIMENTO, 1999. Anais... São Paulo, 1999.

SCHUMPETER, J. History of economic analysis. New York: Oxford University Press, 1954.

SILVA, T.; PEREIRA, M. F.; COSTA, A. M.; HINTERLANG, C. Metodologia em voga no campo de empreendedorismo: emprego de métodos quantitativos para o estudo das características inerentes aos empreendedores. Revista Ibero-Americana de Estratégia, v. 12, n. 4, p. 181-209, 2013.

SPARROW, P. R.; BOGNANNO, M. Competency Requirement Forecasting: Issues for International Selection and Assessment. In: MABEY, C.; ILES, P. Managing Learning. Londres: Routledge, 1994. p. 57-69.

STROBINO, M. R. C.; TEIXEIRA, R. M. Empreendedorismo feminino e o conflito trabalho-família: estudo de multicasos no comércio de material de construção da cidade de Curitiba. Revista de Administração, v. 49, n. 1, p. 59-76, 2014.

TAKAHASHI, A. R. W.; GRAEFF, J. F.; TEIXEIRA, R. M. Planejamento estratégico e gestão feminina em pequenas empresas: o caso das escolas particulares em Curitiba-Paraná. Organizações \& Sociedade, v. 13, n. 39, p. 29-44, 2006.

VALE, G. M. V. Empreendedor: origens, concepções teóricas, dispersão e integração. Revista de Administração Contemporânea, v. 18, n. 6, p. 874-891, 2014.

VIDIGAL, P. R.; NASSIF, V. M. J. A relevância dos aspectos cognitivos e afetivos nas ações dos empreendedores em seus empreendimentos. Revista Alcance, v. 20, n. 1, p. 38-57, 2013.

VITA, L.; MARI, M.; POGGESI, S. Women entrepreneurs in and from developing countries: Evidences from the literature. European Management Journal, v. 32, n. 3, p. 451-460, 2014.

YAMAKAWA, Y.; PENG, M. W.; DEEDS, D. L. Rising from the ashes: Cognitive determinants of venture growth after entrepreneurial failure. Entrepreneurship Theory and Practice, v. 39, n. 2, p. 209-236, 2015.

ZARIFIAN, P. Objetivo Competência: por uma nova lógica. São Paulo: Atlas, 2001. 